\title{
Erratum: X-ray micro-beam characterization of lattice rotations and distortions due to an individual dislocation
}

Felix Hofmann, Brian Abbey, Wenjun Liu, Ruqing Xu, Brian F. Usher, Eugeniu Balaur \& Yuzi Liu

Nature Communications 4:2774 doi: 10.1038/ncomms3774 (2013); Published 12 Nov 2013; Updated 31 Jan 2014

This Article contains an error in Fig. 4 that was introduced during the production process. In Fig. 4c, the $y$-axis scale was mislabelled. The correct version of Fig. 4 appears below.
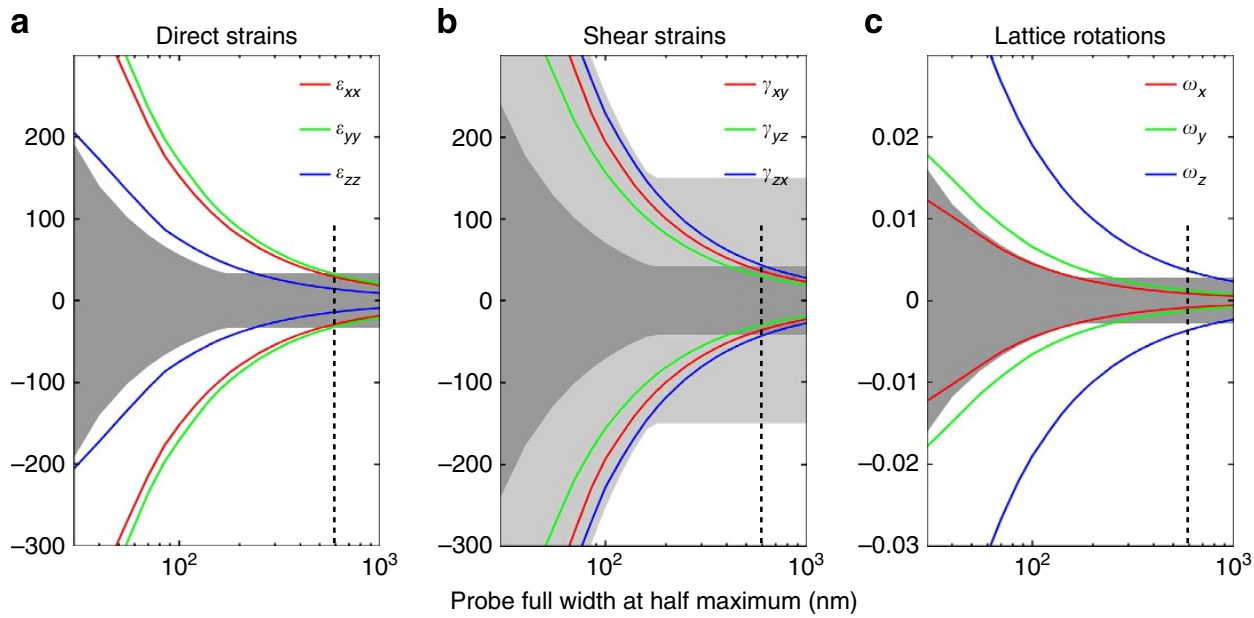

Figure 4 